\title{
An Efficient Synthesis of Tenofovir (PMPA): A Key Intermediate Leading to Tenofovir-based HIV Medicines
}

Brenden P. Derstine, ${ }^{\dagger}$ John W. Tomlin, ${ }^{\dagger}$ Cheryl L. Peck, ${ }^{\dagger}$ Jule-Phillip Dietz, ${ }^{\star}$ Brenden T. Herrera,

${ }^{\dagger}$ Flavio S. P. Cardoso, ${ }^{\dagger}$ Dinesh J. Paymode,${ }^{\dagger}$ Andrew C. Yue, ${ }^{\dagger}$ Anthony J. Arduengo III, ${ }^{\S}$ Till Opatz, ${ }^{\dagger}$ David R. Snead, ${ }^{\dagger}$ Rodger W. Stringham, ${ }^{\dagger}$ D. Tyler McQuade ${ }^{* \dagger}$ and B. Frank Gupton ${ }^{* \dagger}$

${ }^{\dagger}$ Department of Chemical and Life Sciences Engineering, Virginia Commonwealth University, Richmond, Virginia 23284, United States

${ }^{\ddagger}$ Department of Chemistry, Johannes Gutenberg-University, Duesbergweg 10-14, 55128 Mainz, Germany

${ }^{\S}$ Department of Chemistry, The University of Alabama, Tuscaloosa, Alabama 35487, United States

Keywords: tenofovir $\bullet$ hydroxypropyl adenine $\bullet$ hydroxypropyl imidazole $\bullet$ diaminomaleonitrile - flow chemistry

Abstract: Herein, we report further improvements to the synthesis of tenofovir 1, the precursor to tenofovir disoproxil fumarate and tenofovir alafenamide fumarate. Starting from acyclic precursor diaminomalononitrile 12, a four-step protocol to tenofovir $\mathbf{1}$ will allow for vertical integration for 
more manufacturers. The key transformation is a more convergent one step procedure from $\mathbf{6}$ as compared to the current commercial process, with an improved yield from $59 \%$ (two steps) to 70\%. Further improvements include eliminating the need for problematic magnesium tertbutoxide (MTB) and significant solvent reduction by eliminating the need for an intermediate workup. With the costs of HIV/AIDS treatments remaining a barrier for those most in need, lowering the raw material/processing costs and increasing the security of supply can increase patient access.

\section{INTRODUCTION:}

In 2018, the World Health Organization (WHO) reported that only $60 \%$ of the 25 million people in the developing world living with HIV/AIDS were receiving treatment. While drug regimen costs are low from a Western perspective $-\$ 60-70 /$ patient/year, the costs remains too high to ensure that all who need the medicines gain access. Cost reduction can be achieved by using lower cost raw materials and by streamlining the manufacturing processes. We predict that new routes that leverage alternative starting materials will incentivise a different spectrum of market participants relative to the state of practice. For example, most TDF manufacturing processes start with adenine and propylene carbonate. A new process that starts from hydrogen cyanide and a chiral amine might appeal to a different set of producers who are basic in hydrogen cyanide handling. The number of intermediate and active ingredient manufacturers is known to correlate with the products price - increased competition encourages lower prices in these high volume medicine markets. 

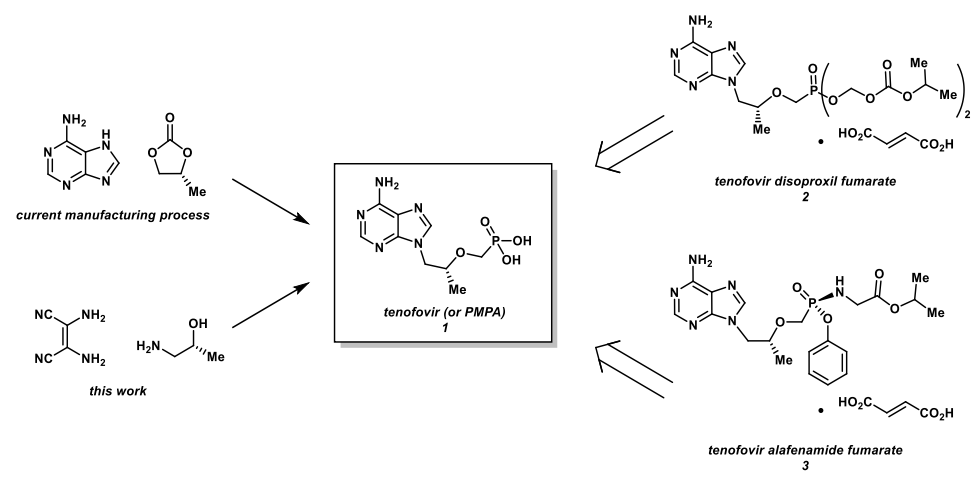

Scheme 1. Synthetic Strategies for tenofovir disoproxil fumarate and tenofovir alafenamide fumarate.

Tenofovir disoproxil fumarate (TDF, 2 ) is a pro-drug of the nucleotide analogue reverse transcriptase inhibitor (NRTI) tenofovir (PMPA, 1) that was developed for the treatment of HIV/AIDS and hepatitis B (Scheme 1). ${ }^{2-4}$ TDF is currently used as a frontline treatment for patients with HIV/AIDs and over 1600 MT were produced in 2019 with a forecasted demand of greater than $1700 \mathrm{MT}$ in $2020 .^{5,6}$ The first-generation manufacturing process for TDF was described by Gilead Sciences Inc. (Scheme 2). ${ }^{2}$ Adenine was transformed into TDF in a threestage, four-step sequence. The lone stereocenter is installed in Stage 1 via alkylation of adenine with $(R)$-propylene carbonate (5). Base-mediated alkylation of the resulting secondary alcohol with tosylated diethyl (hydroxymethyl)phosphonate (DESMP, 8) gave the intermediate phosphonate ester (not shown). The free phosphonic acid PMPA (1) is formed by action of TMSBr and then esterified with chloromethyl isopropyl carbonate (CMIC, 9) to yield crude tenofovir disoproxil (TD, 10). Treatment of crude TD with fumaric acid gives crystalline TDF in a $13 \%$ overall yield. 


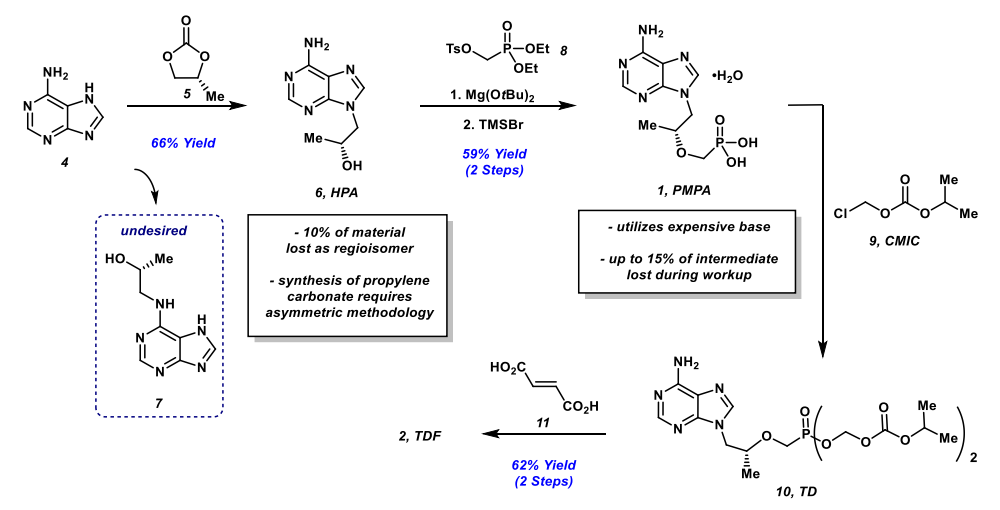

Scheme 2. Current manufacturing process for tenofovir disoproxil fumarate.

The manufacturing process described in Scheme 1 was improved by Clinton Health Acess Initiative (CHAI) to give TDF in a $24 \%$ yield. ${ }^{7}$ Currently, TDF is being synthesized commercially by at least 17 manufacturers, including Gilead, Mylan, Hetero, Zhejiang Huahai, Stride, Lupin, Aurobindo and Laurus Labs. According to the United States Agency for International Development (USAID), there is very little variation in the manufacturing processes between suppliers; however, incremental improvements have been made to bring the yield of TDF up to $38 \%$. The current manufacturing process continues to offer opportunities for improvement, in particular the first two stages. In Stage 1, the alkylation of adenine results in an regioisomeric impurity (7) - roughly $10 \%$ of the material is lost to undesired $N$-alkylation. ${ }^{5}$ The purity profile can be improved using toluene as an antisolvent but the undesired regioisomer is still present (7$8 \%$ ); however, recrystallization using 1:1 MeOH/iPrOH provided the desired material in $66 \%$ overall yield with $1.7 \%$ of the off-regioisomer remaining. ${ }^{7,8}$ The price of adenine has fluctuated in recent years suggesting that routes that avoid using adenine could improve overall market robustness.

The transformations in Stage 2 pose further challenges. ${ }^{7-11}$ The two reactions are telescoped because the phosphonate ester intermediate is water-soluble, prone to hydrolysis to the monoester 
and difficult to crystallize. Another issue is the base used in Stage 2a to couple the (R)-1-(6-amino9H-purin-9-yl)propan-2-ol (HPA) with DESMP. The base reported most often, $\mathrm{Mg}(\mathrm{O} t \mathrm{Bu})_{2}$, provides excellent conversions $(>90 \%)^{8}$ but has drawbacks including: (1) high cost, (2) poor reproducibility - lot to lot variation, and (3) higher cost workup and purification. ${ }^{7}$ We sought to create a process that avoided adenine, propylene carbonate and $\operatorname{Mg}(\mathrm{O} t \mathrm{Bu})_{2}$. Herein, we describe our approach that delivers high quality $\mathbf{1}$ using alternative starting materials at a cost that is comparable to the existing manufacturing route.

\section{RESULTS AND DISCUSSION:}

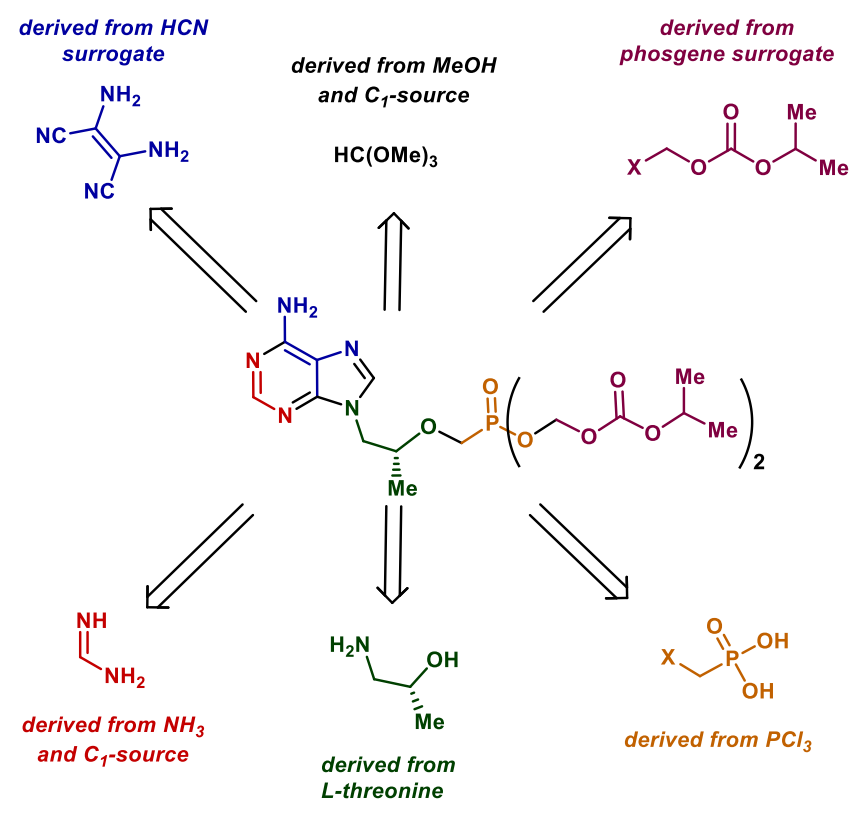

Scheme 3. TDF Atom Assignments Based on Low-Cost,

Commodity Raw Materials. 
We performed a retrosynthetic analysis of PMPA where we constrained our starting materials to low-cost raw materials (Scheme 3). Each proposed fragment can be sourced to simple, highvolume raw materials such as hydrogen cyanide, L-threonine, phosphorous trichloride, ammonia and formaldehyde. In addition, we defined a process which facilitates the synthesis of both tenofovir medicines TDF and tenofovir alafenamide fumarate (TAF, 3). As $\mathbf{1}$ is a common intermediate in both TDF and TAF syntheses, targeting 1 for improvement was deemed a high priority.

We considered many strategies and the most promising was identified to include 5-amino-4cyanoimidazole bearing a chiral hydroxypropyl arm at N1 (HPI, 15) as an intermediate. Nippon Soda Company describe the synthesis of $\mathbf{1 5}$ from $\mathbf{1 2}$ in a patent giving us hope that a market for this material might be possible. ${ }^{12}$ The Nippon Soda Company's original route provided overall modest yields $(\sim 50 \%)$ and in our hands had a very challenging work-up where viscous polycyanide polymers clogged filters and colored solutions a deep red color that was hard to remove from product. While these types of substrates (15, included) are commonly used to construct functionalized imidazoles and nucleobases, ${ }^{13-15}$ the synthetic routes often suffer the same challenges. The route needed process improvements if the chemistry were to become more viable.

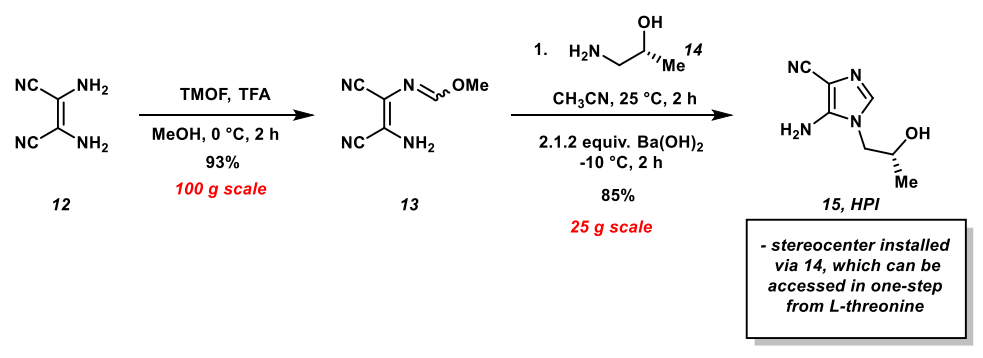

Scheme 4. Synthesis of HPI (15) Utilizing Low-Cost Reagents 
Scheme 4 depicts our improved route to 15 . The process begins by condensing diaminomaleonitrile (DAMN), a commercially available tetramer of $\mathrm{HCN}$, and trimethylorthoformate (TMOF) yielding formimidate $\mathbf{1 3}$ in good yield. The addition of $(R)-1$ aminopropan-2-ol (14 - one step from L-theonine $)^{16}$ yielded the formamidine intermediate that cyclizes to $(R)$-5-amino-1-(2-hydroxypropyl)-1H-imidazole-4-carbonitrile, (HPI, 15) in 85\% yield using $\mathrm{Ba}(\mathrm{OH})_{2} \cdot{ }^{17}$ Swapping the based used in the original Nippon Soda Company patent $(\mathrm{NaOH})$ with $\mathrm{Ba}(\mathrm{OH})_{2}$ eliminated the polycyanide tars during crystallization enabling easier isolation, higher yields and product with little color.

We proceeded to investigate cyclization conditions to form the adenine core (Scheme 5). Initial studies were conducted using formamidine acetate in diglyme affording 6 with high conversion as monitored by HPLC. The use of diglyme as the solvent presented two challenges: 1) crystallization of the product was variable often yielding a black oil;2) diglyme is expensive when alternative solvents such as DMF and NMP were considered.

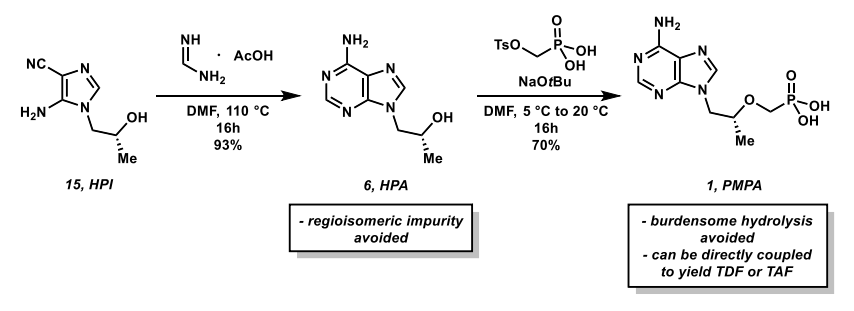

Scheme 5. Novel Synthesis of PMPA Utilizing the HPI Intermediate.

DMF and NMP were investigated with DMF providing higher yields. Using DMF, the reaction proceeded in high conversion and purification was easily achieved using 1:1 (v:v) isopropanol/ $\mathrm{MeOH}^{7,8}$ as anti-solvent (CHAI process) once the DMF was removed. However, initial studies with these isolation conditions proved to be not translatable to larger scale reactions, warranting further investigations. Screening alternative anti-solvents and crystallization conditions 
were conducted to maximize the isolated yield (See Supporting Information for details). Anhydrous isopropanol at $-15^{\circ} \mathrm{C}$ furnished $\mathrm{HPA}$ in $93 \%$ yield and $99 \%$ purity on a 25 -gram scale. Further details on process optimization and reproducibility are available in the Supporting Information.

Producing PMPA via a more efficient alkylation that avoided the $\mathrm{Mg}(\mathrm{O} t \mathrm{Bu})_{2}$ became our next focus. We hypothesized that convergency could be increased by introducing the phosphonate bond via the ((tosyloxy)methyl)phosphonic acid. We hypothesized that this approach might also enable us to avoid using $\mathrm{Mg}(\mathrm{O} t \mathrm{Bu})_{2}$.

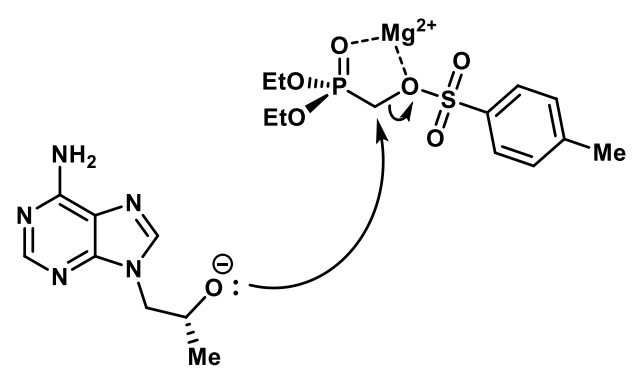

Figure 1. Putative Role of $\mathrm{Mg}^{2+}$

Counterion in Alkylation Reaction.

We tested our hypothesis by screening the reaction shown in Table 1 where the type of base and solvent were varied. Based on previous reports where the $\mathrm{Mg}^{2+}$ counterion proved critical to coupling, we screened a range of lower cost magnesium-derived bases (Figure 1). Using 3 - 5 equivalents at room temperature in polar aprotic solvents such as DMPU or NMP, no desired product was observed (entries 1-5, Table 1). ${ }^{7,8}$ Previous reports of PMPA and derivatives thereof discussed bases with lithium or sodium as the counterion. ${ }^{18}$ LiHMDS was also investigated because lithium cations are known to engage multiple coordination partners. The use of LiHMDS regardless of solvent, provided lower conversion (e. g. entry 6). Extending the screen to higher 
temperatures while maintaining 3 equivalents of base $\left(70{ }^{\circ} \mathrm{C}\right.$, entries 7$)$ gave trace amounts of PMPA (Table 1) with $\mathrm{NaO} t \mathrm{Bu}$ giving the best results $(20-25 \%)$. Further studies indicated that the yield of PMPA was improved to $64 \%$ by increasing the loading of $\mathrm{NaO} t \mathrm{Bu}$ to 7 equivalents and maintaining a reaction temperature of $70{ }^{\circ} \mathrm{C}$. Lewis acids were also investigated as potential candidates for facilitating $O$-alkylation via activation of the leaving group. A variety of di- and trivalent cations were screened but improved conversions were not realized.

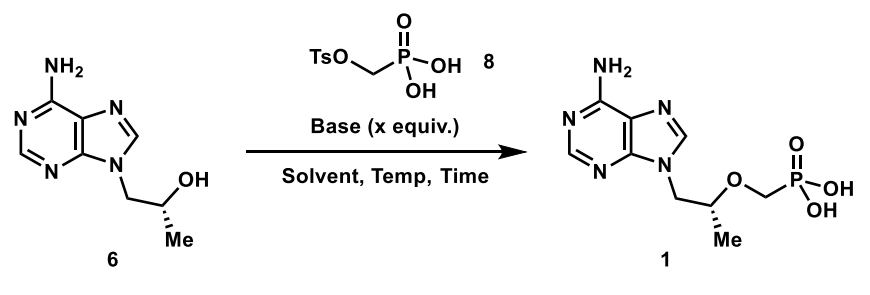

\begin{tabular}{|c|c|c|c|c|c|c|}
\hline Entry & Base & $\begin{array}{c}\text { Equiv } \\
.\end{array}$ & Solvent & Time & $\begin{array}{c}\text { Temp } \\
\left({ }^{\circ} \mathrm{C}\right)\end{array}$ & $\underset{\mathrm{b}}{\text { Yield }}$ \\
\hline 1 & $\mathrm{MeMgCl}$ & 3 & DMPU & $7 \mathrm{~h}$ & 25 & 0 \\
\hline 2 & $\mathrm{MeMgCl}$ & 3 & NMP & $7 \mathrm{~h}$ & 25 & 0 \\
\hline 3 & $i \mathrm{PrMg} \cdot \mathrm{LiCl}$ & 3 & DMPU & $7 \mathrm{~h}$ & 25 & 0 \\
\hline 4 & $i \mathrm{PrMg} \cdot \mathrm{LiCl}$ & 3 & NMP & $7 \mathrm{~h}$ & 25 & 0 \\
\hline 5 & $\mathrm{Mg}(\mathrm{HMDS})_{2}$ & 3 & DMPU & $7 \mathrm{~h}$ & 25 & 0 \\
\hline 6 & LiHMDS & 3 & DMPU & $7 \mathrm{~h}$ & 25 & 21 \\
\hline 7 & $\mathrm{NaO} t \mathrm{Bu}$ & 3 & NMP & $12 \mathrm{~h}$ & 70 & 25 \\
\hline 8 & $\mathrm{NaO} t \mathrm{Bu}$ & 5 & DMF & $7 \mathrm{~h}$ & 70 & 61 \\
\hline $9^{c}$ & $\mathrm{NaO} t \mathrm{Bu}$ & 6 & DMF & $16 \mathrm{~h}$ & 25 & 70 \\
\hline 10 & $\mathrm{KO} t \mathrm{Bu}$ & 3 & NMP & $3 \mathrm{~h}$ & 70 & 0 \\
\hline
\end{tabular}

\footnotetext{
${ }^{a}$ We found the free phosphonic acid to be interchangeable with the pyridinium phosphonate salt. HPA $(2.4 \mathrm{mmol})$, tosylphosphonic acid $(4.8 \mathrm{mmol})$, Solvent $(1.5 \mathrm{~mL})$; see supporting information. ${ }^{b}$ Determined by HPLC. ${ }^{\mathrm{c}}$ The equivalents of the tosylphosphonic acid was 1.7 for this experiment.
}

In general, we observed sodium-derived bases led to higher conversions and the $\mathrm{pK}_{\mathrm{a}}$ of the base was found to be critical to the chemoselectivity of the alkylation reaction; alkoxide bases favored 
$O$-alkylation while nitrogenous and alkyl-organometallic bases led to significantly more $N$ alkylation. Finally, polar aprotic solvents (DMF, DMPU, NMP) consistently gave the highest conversion of PMPA. Thus, we moved towards optimizing the coupling between HPA and the tosylphosphonic acid using $\mathrm{NaO} t \mathrm{Bu}$ in $\mathrm{DMF}$. We turned our attention back to the temperature of the coupling of the reaction, postulating that the reaction could be conducted at room temperature. With 7 equivalents of $\mathrm{NaO} t \mathrm{Bu}$ and 1.7 equivalents of the tosylphosphonic acid in $\mathrm{DMF}$ at room temperature, the coupling was observed to proceed with high conversion and an average isolated yield of $68 \%$. Further investigation into the balance between the equivalents of base and phosphonic acid led to the optimized reaction parameters: 6 equivalents $\mathrm{NaO} t \mathrm{Bu}, 1.7$ equivalents of the tosylphosphonic acid in DMF at room temperature for 16 hours (Table 1). Yields have been reproducible around $70 \%$ and the reaction has been conducted on a 25 -gram scale. More importantly, the convergent process is another significant improvement to the Gilead and CHAI processes. The outcome is overall higher yields and decreased purification and processing costs. Further development of this chemistry into a scalable process is described in the Supporting Information. We have developed step-wise experimental descriptions which are presented in the Supporting Information and are designed to help those who wish to implement the process, actual batch sheets are available upon request.

We recognize that other modalities exist beyond batch approaches and we explored alternatives. We set out to develop a through process to reduce unit operations. Scheme 6 illustrates the basic approach. We chose a commercial peristaltic pump-based reactor system fitted with a solid column of $\mathrm{NaOH}$ to demonstrate that a through process from 12 to 15 was possible. 


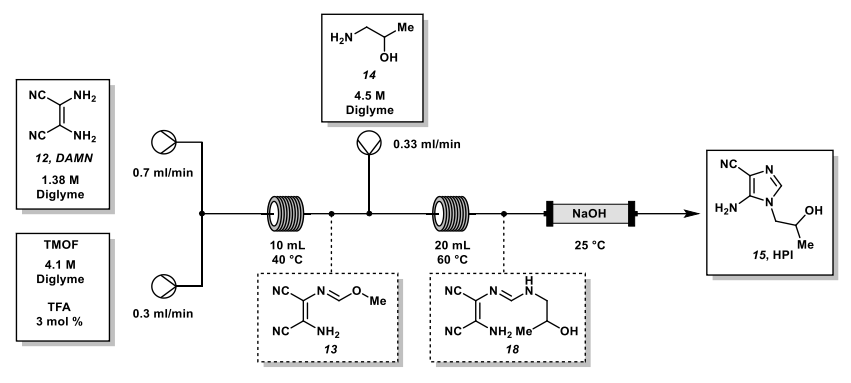

Scheme 6. Continuous Process for the Preparation of HPI.

The continuous process maintains a similar sequence of synthetic steps compared to the batch process with a couple of noteworthy differences. We found that diglyme was necessary to ensure that all starting materials remained soluble and to enable complete end-to-end telescoping. The process was initiated by combining DAMN (1.38M in diglyme) with TMOF (4.1M) and (TFA 3\% $\mathrm{w} / \mathrm{w}$ ) to form the imidate followed by condensation with the optically active amine. The imidate intermediate (18) was then cyclization by passing through a column filled with $\mathrm{NaOH}$.

While this flow process has many advantages (few unit operations, a single solvent), the process has liabilities. At optimal performance, the system had a productivity of 8 grams/hr. of HPI (15); however, the quality of the HPI degraded over time. We hypothesized that this performance decline resulted from precipitation of cyanide oligomers onto the surface of the sodium hydroxide pellets. The cyanide oliogmers result as a byproduct of the annulation. ${ }^{19}$ When the reaction mixture first entered the hydroxide-column, the color of the solution was pale-yellow throughout the residence time. After just a few minutes, the column begins to be stained with brown/red/black material. After a few hours, the color of the solution that exited the column became darker brown as the loading capacity of the column was exceeded. Regardless, we were able to demonstrate that for those manufacturers leveraging continuous processes, our overall approach might eventually yield an end-to-end through process. The $\mathrm{NaOH}$ column issue could be solved by using a continuous 
stirred tank reactor (CSTR) containing our $\mathrm{Ba}(\mathrm{OH})_{2}$ approach we described in the batch section. Our objective was to demonstrate the basic concept in this case.

In summary, we have reported several advancements - both batch and flow processes - towards the synthesis of tenofovir (PMPA, 1). We have demonstrated that the functionalized adenine core can be constructed from high-volume, low-cost commodity materials. The transformations are efficient, show promise for further scaling (we demonstrated a minimum of $25 \mathrm{~g}$ scale) and increase the potential for new market entrants to participate. Tenofovir is a key intermediate in TDF and TAF, with the former being produced on $1600 \mathrm{MT}$ per annum and sold for $\$ 140 / \mathrm{kg}$. A $10 \%$ reduction in cost of goods amounts to a savings of $\$ 22.4$ million/year - resources that procurers can use to purchase more medicines.

\section{EXPERIMENTAL}

Reactions were monitored by GC-MS or HPLC using the methods indicated. Formation of MADI, including the amidine intermediate was monitored via GC-MS. The column used was an Agilent J\&W GC column, type HP-1 (30 m x $0.320 \mathrm{~mm}, 5 \mu \mathrm{m}$ film). The oven was maintained at $200{ }^{\circ} \mathrm{C}$ and the inlet at $225^{\circ} \mathrm{C}$ for the duration of the method (20 minutes). A split ratio of 50:1 was used. The flow rate was $0.8 \mathrm{~mL} / \mathrm{min}$ with helium as the carrier gas. HPI, HPA and PMPA were monitored using identical HPLC methods. The mobile phase was a mixture of $15 \% \mathrm{MeOH}$ and $85 \%$ aqueous potassium phosphate buffer $(\mathrm{pH} 7.6,10 \mathrm{mM})$. The chromatograms were acquired on an Agilent 1100 system using an Agilent Extend C18 column (5 $\mu \mathrm{m}, 4.6 \mathrm{~mm}$ x 250 $\mathrm{mm}$ ) and were monitored at 245 (HPI) and $260 \mathrm{~nm}$ (HPA and PMPA). 
Preparation of methyl $\mathrm{N}$-2-amino-1,2-dicyanovinyl)formimidate (MADI), 13: To a 2-L three-neck round bottom flask equipped with an overhead stirrer and thermocouple was charged 2,3-diaminomaleonitrile (DAMN), 12, (100 g, 1.0 equiv., $926 \mathrm{mmol})$ and reagent grade $\mathrm{MeOH}$ $(400 \mathrm{~mL})$. The mixture was stirred at room temperature for 5 minutes. Trimethyl orthoformate (TMOF) (120 mL, 1.2 equiv., $1.11 \mathrm{~mol})$ was charged to the reaction mixture in one portion. Afterwards, trifluoroacetic acid (TFA) $(50 \mu \mathrm{L}, 0.005$ equiv, $4.63 \mathrm{mmol})$ was charged to the reaction in one portion. (This reaction is rapid and results in a thick slurry within 5 minutes, therefore, overhead stirring is required. Additionally, care should be taken to avoid adding excess TFA as this causes the reaction mixture to thicken to a viscosity where stirring is challenging. Poor mixing results in lower isolated yields.) The reaction was heated to an internal temperature of $40^{\circ} \mathrm{C}$ and stirred for 2 hours. After consumption of the starting materials as determined by GCMS, reagent grade hexanes $(600 \mathrm{~mL})$ was charged to the reaction mixture in one portion. The suspension was allowed to slowly cool to room temperature over the course of approximately 20 minutes, then cooled to an internal temperature $0{ }^{\circ} \mathrm{C}$ and stirred an additional hour. The solids were isolated by vacuum filtration and dried under vacuum to afford a pale-yellow solid, 13, in 93\% yield (128.9 g), with an GC-MS assay purity of 98\%. ${ }^{1} \mathrm{H}-\mathrm{NMR}\left(600 \mathrm{MHz}, \mathrm{DMSO}-\mathrm{d}_{6}\right): \delta=$ $7.98(\mathrm{~s}, 1 \mathrm{H}), 7.04(\mathrm{bs}, 2 \mathrm{H}), 3.82(\mathrm{~s}, 3 \mathrm{H}) \mathrm{ppm} .{ }^{13} \mathrm{C}-\mathrm{NMR}\left(150 \mathrm{MHz}, \mathrm{DMSO}-\mathrm{d}_{6}\right): \delta=156.8,123.0$, 114.8, 114.6, 98.2, 54.6 ppm. FTIR (ATR, neat) 3466, 3356, 2238, 2196, 1636, 1606, 1369, 1271, 912, 799, $501 \mathrm{~cm}^{-1}$. HRMS (ESI) $\mathrm{m} / \mathrm{z}$ calculated for $\mathrm{C}_{6} \mathrm{H}_{6} \mathrm{~N}_{4} \mathrm{OH}[\mathrm{M}+\mathrm{H}]^{+}$151.0620, found 151.0614 .

\section{Preparation of $(R)-5$-amino-1-(2-hydroxypropyl)-1H-imidazole-4-carbonitrile (HPI), 15:}

To a 500-mL three-neck round bottom flask fitted with an internal temperature probe was added 
(R)-1-aminopropan-2-ol, 14, (18.2 mL, $231 \mathrm{mmol}, 1.4$ equiv.) and $\mathrm{MeCN}$ (25 mL) at room temperature. The solution was stirred for 5 minutes. MADI, 13, (25.0 g, 167 mmol, 1.0 equiv.) was suspended in $\mathrm{MeCN}(175 \mathrm{~mL})$ and charged to the reaction mixture. Additional MeCN (15 $\mathrm{mL}$ ) was used to rinse the reactor walls to rinse down any adhering solid. After addition of MADI, the reaction mixture turned dark brown and was stirred at room temperature for 2.5 hours. Conversion to the desired amino-alcohol intermediate was monitored by HPLC while the consumption of MADI was monitored by GC-MS. After complete conversion, the reaction mixture was cooled to an internal temperature of $0-5{ }^{\circ} \mathrm{C}$ using an ice bath. Solid $\mathrm{Ba}(\mathrm{OH})_{2}$ monohydrate (37.9 g, 200 mmol, 1.2 equiv.) was charged with deionized $\mathrm{H}_{2} \mathrm{O}(113.7 \mathrm{~mL})$. The reaction was warmed to room temperature. As the reaction proceeded, the color turned from bright red to dark brown with visible precipitate stirring at the bottom of the flask. Complete conversion to the desired HPI product occurred at 1 hour 15 min as tracked by HPLC.

After 1 hour 15 min, the reaction mixture was filtered on a Büchner funnel and the round bottom flask was rinsed with $\mathrm{MeCN}(3 \times 25 \mathrm{~mL})$ to give a total volume of approximately $300 \mathrm{~mL}$. This was concentrated to approximately $200 \mathrm{~mL}$ via rotary evaporation under reduced pressure at 40 ${ }^{\circ} \mathrm{C}$. The solution was then heated to $50{ }^{\circ} \mathrm{C}$ at which time the mixture turned dark brown. After stirring in a $40{ }^{\circ} \mathrm{C}$ oil bath for 10 minutes, the solution was charged with DCM $(200 \mathrm{~mL})$ in one portion and allowed to cool to room temperature over the course of 1 hour. The mixture became biphasic with a black oil visible in the bottom of the flask. The solution was then cooled to an internal temperature of $0-5^{\circ} \mathrm{C}$ and stirred for an additional 1 hour. Upon cooling, precipitation was observed and the mixture was filtered on a Büchner funnel with the black oil remaining in the filtrate to afford HPI as a pale grey solid. The solid was dried under vacuum to yield $23.7 \mathrm{~g}$ of product in an $82 \%$ yield with a 96\% HPLC purity based on peak area. ${ }^{1} \mathrm{H}-\mathrm{NMR}(600 \mathrm{MHz}$, DMSO- 
$\left.\mathrm{d}_{6}\right): \delta=7.11(\mathrm{~s}, 1 \mathrm{H}), 6.07(\mathrm{~s}, 2 \mathrm{H}), 5.06(\mathrm{~s}, 1 \mathrm{H}), 3.85-3.69(\mathrm{~m}, 2 \mathrm{H}), 3.65-3.50(\mathrm{~m}, 1 \mathrm{H}), 1.03(\mathrm{~d}$, $J=3.9 \mathrm{~Hz}, 3 \mathrm{H}) \mathrm{ppm} .{ }^{13} \mathrm{C}-\mathrm{NMR}\left(150 \mathrm{MHz}, \mathrm{DMSO}-\mathrm{d}_{6}\right): \delta=147.9,133.5,117.6,90.1,64.8,50.1$, 20.6 ppm. FTIR (ATR, neat) 3159, 2208, 1570, 1174, $1090 \mathrm{~cm}^{-1}$. HRMS (ESI) $\mathrm{m} / \mathrm{z}$ calculated for $\mathrm{C}_{7} \mathrm{H}_{10} \mathrm{~N}_{4} \mathrm{OH}[\mathrm{M}+\mathrm{H}]^{+}$167.0933, found 167.0926.

Preparation of $(\boldsymbol{R})-1$-(6-Amino-9H-purin-9-yl)propan-2-ol (HPA), 6: To a 500-mL 3-necked round bottom flask, the mixture of $(R)$-5-amino-1-(2-hydroxypropyl)-1H-imidazole-4carbonitrile, 15, (HPI, 97.8\% purity) (25.0 g, $150 \mathrm{mmol}, 1.0$ equiv.) and formamidinium acetate (26.6 g, $256 \mathrm{mmol}, 1.7$ equiv.) was added in DMF (50 mL). The reaction vessel was equipped with a J-KEM internal temperature probe and the mixture was heated to an internal temperature of 100 ${ }^{\circ} \mathrm{C}$ for 16 hours. After completion of the reaction as monitored by HPLC, the heating was turned off and isopropyl alcohol $(150 \mathrm{~mL})$ was added. The reaction mixture was cooled down to room temperature $\left(25^{\circ} \mathrm{C}\right)$. The reaction mixture was cooled to an internal temperature of $-15^{\circ} \mathrm{C}$ and stirred for three hours at same temperature. The suspension was filtered and washed with cold isopropanol $(38 \mathrm{~mL}+37 \mathrm{~mL})$. The isolated solid was dried in vacuum oven at $65^{\circ} \mathrm{C}$ for two hours to afford $(R)-1-(6-a m i n o-9 H-p u r i n-9-y l) p r o p a n-2-o l$ (HPA), 6, as a white solid, (26.67 g, 93\% adjusted with a purity of $99 \%$ by HPLC. The spectroscopic data are in accordance with reported values. ${ }^{1} \mathrm{H}$ NMR (600 MHz, DMSO) $\delta=8.13(\mathrm{~s}, 1 \mathrm{H}), 8.05(\mathrm{~s}, 1 \mathrm{H}), 7.18(\mathrm{~s}, 2 \mathrm{H}), 5.04$ (bs, 1H), $4.18-4.05(\mathrm{~m}, 1 \mathrm{H}), 4.05-3.94(\mathrm{~m}, 2 \mathrm{H}), 1.06(\mathrm{~d}, J=5.9,3 \mathrm{H}) \mathrm{ppm} .{ }^{13} \mathrm{C}$ NMR $(150 \mathrm{MHz}, \mathrm{DMSO})$ $\delta=155.9,152.2,149.7,141.5,118.5,64.6,50.1,20.9 \mathrm{ppm}$. HRMS (ESI) m/z calculated for $\mathrm{C}_{8} \mathrm{H}_{11} \mathrm{~N}_{4} \mathrm{OH}[\mathrm{M}+\mathrm{H}]^{+}$194.1042, found 194.1040. 


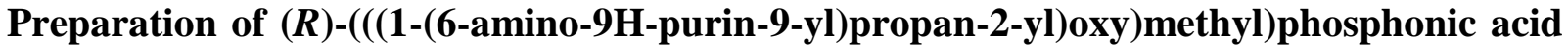

(PMPA), 1: A 500-mL three necked round bottom flask was equipped with a J-KEM internal temperature probe, overhead stirrer and nitrogen line. The flask was charged with anhydrous DMF $(400 \mathrm{~mL})$ and cooled to an internal temperature of $2-5^{\circ} \mathrm{C}$ under an atmosphere of nitrogen. With stirring (300 RPM), sodium tert-butoxide (74.5 g, $776 \mathrm{mmol}, 6.0$ equiv.) was charged to the reaction vessel to afford a clear solution and a temperature increase of $12{ }^{\circ} \mathrm{C}$ was observed. To the clear solution was added ( $R$ )-1-(6-amino-9H-purin-9-yl)propan-2-ol (HPA, 92\% purity) (25.0 g, $129.4 \mathrm{mmol}, 1.0$ equiv.) over 10 minutes with stirring ( $5 \mathrm{x} 5 \mathrm{~g}$ portions). The yellow solution was stirred at an internal temperature of $5{ }^{\circ} \mathrm{C}$ for 30 minutes. Solid ((tosyloxy)methyl)phosphonic acid, 8, (58.5 g, $220 \mathrm{mmol}, 1.7$ equiv.) was added over 10 minutes in four portions ( 14.6 g portions), the internal temperature was not allowed to exceed $15{ }^{\circ} \mathrm{C}$. After the addition was complete, the reaction mixture was warmed to room temperature overnight (16 hours). After complete consumption of the starting material, as indicated by HPLC, the solvent was removed via rotary evaporation under reduced pressure. The residue was dissolved in $250 \mathrm{~mL}$ of water and concentrated hydrochloric acid (approx. $40 \mathrm{~mL}$ ) was added until $\mathrm{pH}=2.8-3.0$. A precipitate formed and the mixture was stirred at an internal temperature of $5{ }^{\circ} \mathrm{C}$ for 3 hours then collected by vacuum filtration. The resulting off white solid was washed with cold $\mathrm{H}_{2} \mathrm{O}(25 \mathrm{~mL})$, a cold 1:1 mixture $\mathrm{H}_{2} \mathrm{O}$ /acetone $(25 \mathrm{~mL})$ and ice-cold acetone $(25 \mathrm{~mL})$. The solid was dried in vacuo at 75 ${ }^{\circ} \mathrm{C}$ overnight to yield PMPA, 1, as a white solid (26.2 g, 70\% adjusted for KF). KF Titration: 2.4\%. The spectroscopic data are in accordance with reported values. ${ }^{1} \mathrm{H}$ NMR $(600 \mathrm{MHz}$, DMSO) $\delta=8.15(\mathrm{~s}, 2 \mathrm{H}), 7.25(\mathrm{~s}, 2 \mathrm{H}), 4.28(\mathrm{dd}, J=14.4,3.7,1 \mathrm{H}), 4.17(\mathrm{dd}, J=14.4,5.6,1 \mathrm{H})$, $3.91(\mathrm{dd}, J=10.7,5.3,1 \mathrm{H}), 3.59(\mathrm{p}, J=13.2,2 \mathrm{H}), 1.03(\mathrm{~d}, J=6.2,3 \mathrm{H}) \mathrm{ppm} .{ }^{13} \mathrm{C}$ NMR $(150$ MHz, DMSO) $\delta=155.8,152.2,149.7,141.6,118.2,75.3(\mathrm{~d}, J=12.1), 64.4(\mathrm{~d}, J=161.7), 46.4$, 
16.9 ppm. ${ }^{31} \mathrm{P}$ NMR (243 MHz, DMSO) $\delta=16.6 \mathrm{ppm} . \mathrm{cm}^{-1}$. HRMS (ESI) m/z calculated for $\mathrm{C}_{9} \mathrm{H}_{14} \mathrm{~N}_{5} \mathrm{O}_{4} \mathrm{PH}[\mathrm{M}+\mathrm{H}]^{+}$288.0862, found 288.0853.

\section{AUTHOR INFORMATION}

\section{Corresponding Author}

*E-mail: bfgupton@vcu.edu

*E-mail: tmcquade@vcu.edu

\section{Funding Sources}

This work was supported by the Bill and Melinda Gates Foundation and the Gottwald Family Foundation.

\section{ACKNOWLEDGMENT}

We thank Hari. P. R. Mangunuru, Andrew R. Ehle, Jenson Verghese, Eric Yu, Erin E. Striker, Daniel Rivalti, Nakul S. Telang, and Saeed Ahmad for providing valuable insights leading to the creation of this manuscript. We also thank our other M4ALL Team Members led by Professor Timothy Jamison and Oliver Kappe for their weekly insights. In addition, we express gratitude to Trevor Laird and John Dillon for their thoughtful commentary and discussion throughout this work. We also thank Silpa Sundaram and Dr. Susan Hershenson for fostering an ecosystem where difficult decisions can be made. 


\section{REFERENCES}

(1) Bumpas J, Betsch E. Exploratory study on active pharmaceutical ingredient manufacturingfor essential medicines. Health, Nutrition and Population Discussion Paper. The World Bank; 2009.

(2) Arimilli, M. N.; Cundy, K. C.; Dougherty, J. P.; Kim, C. U.; Oliyai, R.; Stella, V. J. Antiviral Phosphonomethoxy Nucleotide Analogs Having Increased Oral Bioavailability. US5977089A, November 2, 1999.

(3) Naesens, L.; Bischofberger, N.; Augustijns, P.; Annaert, P.; Mooter, G. V. den; Arimilli, M. N.; Kim, C. U.; Clercq, E. D. Antimicrob. Agents Ch. 1998, 42, 1568-1573.

(4) Robbins, B. L.; Srinivas, R. V.; Kim, C.; Bischofberger, N.; Fridland, A.. Antimicrob. Agents Ch. 1998, 42, 612-617.

(5) Clinton Health Access Initiative. HIV Market Report, Issue 10. September 2019.

(6) Balzarini, J.; Holy, A.; Jindrich, J.; Naesens, L.; Snoeck, R.; Schols, D.; Clercq, E. D. Antimicrob. Agents Ch. 1993, 37, 332-338.

(7) Brown Ripin, D. H.; Teager, D. S.; Fortunak, J.; Basha, S. M.; Bivins, N.; Boddy, C. N.; Byrn, S.; Catlin, K. K.; Houghton, S. R.; Jagadeesh, S. T.; et al. Org. Process Res. Dev. 2010, 14, 1194-1201.

(8) Riley, D. L.; Walwyn, D. R.; Edlin, C. D. Org. Process Res. Dev. 2016, 20, 742-750. 
(9) Vasireddy, U. M. R.; Vellanki, S. R. P.; Balusu, R. B.; Bandi, N. D. R.; Jujjavarapu, P. K.; Ginjupalli, S. R.; Pilli, R. K. Process for the Preparation of Tenofovir. US8049009B2, November $1,2011$.

(10) Indukuri, V. S. K.; Joga, S. R.; Gorantla, S. R.; Chava, S. Process for the Preparation of Tenofovir. WO2013072745A1, May 23, 2013.

(11) Datta, D.; Vellanki, S. R. P.; Sahu, A.; Balusu, R. B.; Ravi, M. R.; Nandipati, H. B.; Rama, S.; Vadali, L. R.; Gorantla, S. S. C.; Dasari, S. R.; et al. Process for the Preparation of Tenofovir Disoproxil Fumarate. US8759515B2, June 24, 2014.

(12) Takase, M.; Komatsu, F. Method for Production of N-(2-Amino-1,2Dicyanovinyl)Imidates, Method for Production of N-(2-Amino-1,2-Dicyanovinyl)Formamidine, and Method for Production of Aminoimidazole Derivatives. US8273899B2, September 25, 2012.

(13) Gosselin, G.; Bergogne, M. C.; De Rudder, J.; De Clercq, E.; Imbach, J. Louis. J. Med. Chem. 1986, 29, 203-213.

(14) Basyouni, W. M.; Hosni, H. M. Egypt. J. Chem. 2001, 44, 251-267.

(15) Kadir, K.; Shaw, G.; Wright, David. J. Chem. Soc., Perkin Trans. 1 1980, 2728-2731.

(16) Rossen, K.; Simpson, P. M.; Wells, K. M. A Practical Synthesis of Both Enantiomers of 1amino-2-propanol and Propylene Oxide. Syn. Comm. 1993, 23, 1071 - 1074.

(17) Alves, M. J.; Booth, B. L.; Proenç, M. F. J. R. P. J. Chem. Soc., Perkin Trans. 1 1990, No. 6, 1705-1712. 
(18) Yu, R. H.; Schultze, L. M.; Rohloff, J. C.; Dudzinski, P. W.; Kelly, D. E.; Org. Process.

Res. Dev. 1999, 3, 53 - 55.

(19) Matthews, C. N. Planet. Space Sci. 1995, 43, 1365-1370.

\section{TABLE OF CONTENTS}

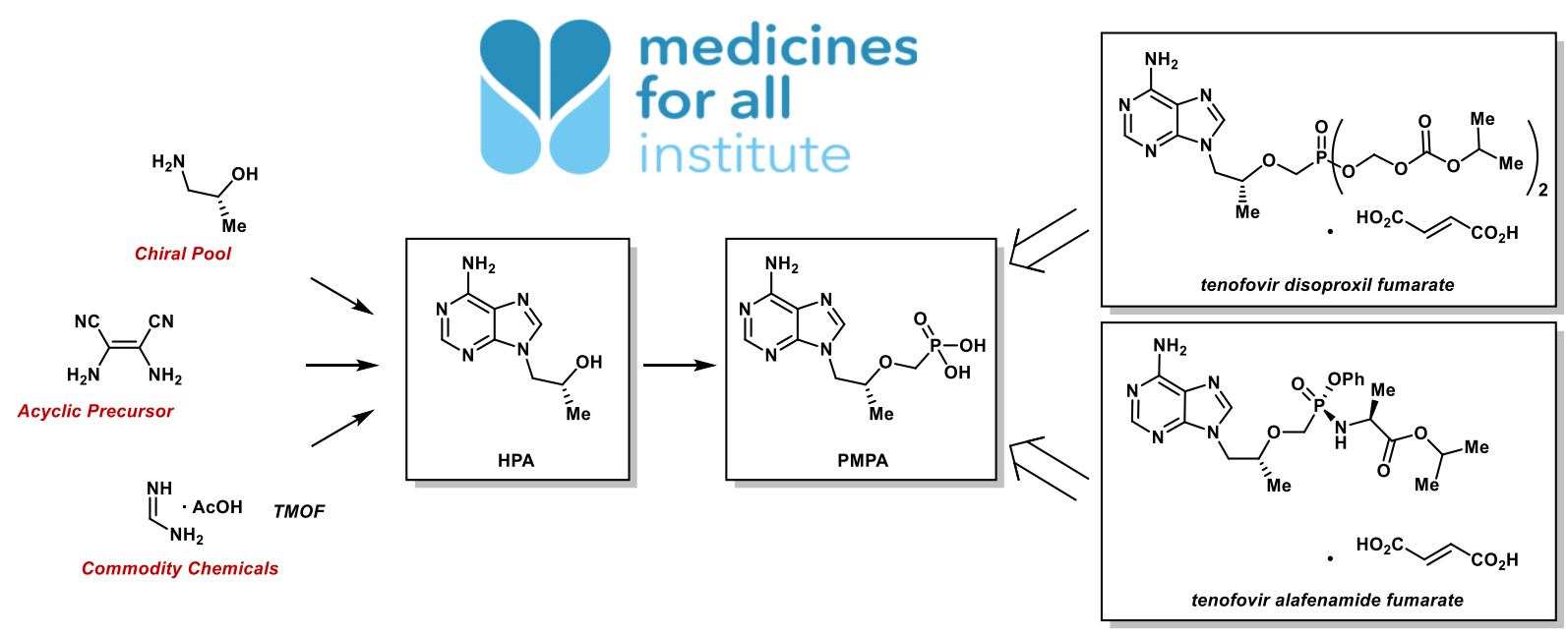

